\title{
FACTORAL STRUCTURE OF MORPHO-FUNCTIONAL INDICATORS AND MOTOR QUALITIES OF MUSCULAR STRENGTH AND ENDURANCE IN STUDENTS
}

\author{
P. Petkov* \\ Department of Physical Education and Sport, Trakia University, Stara Zagora, Bulgaria
}

\begin{abstract}
The purpose of the present study is to establish the factor relationships between morpho-functional parameters and physical qualities, muscle strength and endurance due to the application of a specialized fitness model. To achieve this goal we the following tasks are set: research of literature resources; development and testing of a specialized fitness model; development of a test battery; processing and analyzing the data from the conducted testing. Research methods - pedagogical experiment, testing, factor analysis, graphical analysis. The contingent of the study are 34 students from the Trakia University. The students are on average 20.04 years old. The results and their analysis show that in the applied fitness model there is a decrease in the number of the main factors in the factor structure of the morpho-functional indicators and the observed motor functions; the increase in the influence of the first main factor in the second study explains the higher percentage of the cumulative variance. This leads to structural changes in the content of the main factors; changes the influence of factors, which after the experiment increases the influence of endurance due to the composition of body weight; the force factors retain approximately the same weight in the second study.
\end{abstract}

Key words: experiment, university, circle activities

\section{INTRODUCTION}

Discovering the correlation structure of morpho-functional indicators and motor qualities of muscle strength and endurance in students allows us to trace the relationships between individual indicators and motor qualities.

A natural continuation of the correlation analysis is the factor analysis. Factor analysis is designed to convert a set of correlated data into a new set with non-correlated artificial variables or factors that explain as much of the overall variation of the original data as possible. This technique reduces the number of initial variables by grouping those that correlate with each other in a common factor and dividing the non-correlations into different factors. The main task in factor analysis is to

\footnotetext{
*Correspondence to: Plamen Petkov, Trakia University, Department of Physical Education and Sport, Stara Zagora, Bulgaria, Email: jo_team@abv.bg
}

determine the number of factors $k$, which depends significantly on the strength of the correlations between the data (1).

The performed factor analysis is applied to establish the factor structure of the morphofunctional indicators and the motor qualities observed by us in the experimental group.

The smaller number of latent signs (factors) can explain the variance of a large set of tests. The factors are formed as a result of similar general characteristics of the studied indicators. The factor analysis of the morphofunctional indicators and the motor qualities of the experimental group is based on the method of the main components.

At the beginning and the end of the experimental period, the correlation matrices determined their own meanings, which are arranged in descending order. Eigenvectors larger than one correspond to eigenvectors, which form the main factors (2). 


\section{METHODS}

The aim of the study is to establish the factor relationships between morpho-functional parameters and physical qualities, muscle strength and endurance due to the application of a specialized fitness model.

To achieve this goal the following tasks are set:

1. Study of literature sources.

2. Development and testing of a specialized fitness model.

3. Development of a test battery.

4. Processing and analysis of the data from the conducted testing.

Research methods:

Pedagogical experiment

Testing

Factor analysis
Graphic analysis

The testing was conducted during the winter semester of the 2016/2017 school year. The contingent of the study are 34 students from the Faculty of Agriculture, Faculty of Veterinary Medicine and Faculty of Economics at the Trakia University of Stara Zagora. The subjects are on average 20.04 years old.

\section{RESULTS}

The analysis of the incoming test results shows that there are seven factors. The first weighs 3,570 , the second 2,098 , the third 1,980 , the fourth 1,623 , the fifth 1,454 , the sixth 1,420 and the seventh 1,183. In total, all seven factors explain $74.05 \%$ of the total variance. The data are shown in Table 1.

Table 1. Analysis of the main factors at the beginning of the experiment

\begin{tabular}{|c|c|c|c|c|c|c|c|}
\hline \multirow[b]{2}{*}{ Test } & \multicolumn{7}{|c|}{ Factors (components) } \\
\hline & 1 & 2 & 3 & 4 & 5 & 6 & 7 \\
\hline FAT\% & ,935 & ,020 &,- 026 & ,025 &,- 083 & ,035 & ,077 \\
\hline Muscle mass & ,911 &,- 045 &,- 061 &, 011 &,- 050 &,- 042 &,- 056 \\
\hline TBW\% &,- 894 &,- 006 &, 026 &,- 037 & ,088 &,- 025 &,- 072 \\
\hline Height &, 660 & ,014 & ,188 & ,003 &,- 014 &,- 180 &,- 409 \\
\hline Height to failure &,- 528 &,- 064 & ,138 &, 135 & ,499 & ,409 &,- 164 \\
\hline Kuper's Test &, 155 & ,885 & ,146 &,- 070 &, 026 &,- 010 &, 159 \\
\hline Beep test &,- 208 & ,732 & ,138 &,- 032 &,- 020 &,- 040 &,- 029 \\
\hline Chest circuit - difference &,- 065 &,- 553 & ,457 &,- 168 &,- 254 &, 046 &, 098 \\
\hline Plank &,- 094 & ,037 & ,833 & ,243 &, 031 &,- 005 &,- 017 \\
\hline Shuttle $10 \times 10 \mathrm{~m}$ &, 000 &,- 178 &,- 686 & , 186 &,- 109 &,- 009 &, 009 \\
\hline $\begin{array}{l}\text { Step test - heart rate beginning }-3^{\text {-rd }} \text { minute of the } \\
\text { recovery }\end{array}$ & 014 &,- 190 &,- 180 & ,816 &, 060 &,- 052 & ,063 \\
\hline Abdominal presses until failure &,- 076 & ,075 & , 198 & 643 &, 061 &,- 527 &,- 032 \\
\hline Dumbbell retention $2 \mathrm{~kg}$ &, 149 & ,294 & ,335 &, 592 &,- 187 & 182 &, 190 \\
\hline Jump length from one place &,- 264 &, 080 & 031 &,- 065 & ,859 &,- 046 &, 002 \\
\hline State power & ,347 &, 100 &, 512 &, 159 &, 528 &,- 108 & ,213 \\
\hline Throwing a medical ball forward &, 105 & ,447 & ,217 &,- 039 &, 165 & ,697 &,- 154 \\
\hline FVC &,- 207 &,- 298 &,- 098 &,- 063 &,- 154 &, 630 & ,074 \\
\hline Push-ups with knee supports until failure &,- 007 &, 045 & ,055 & , 105 & 011 &,- 048 & ,907 \\
\hline $\begin{array}{c}\text { Total } \\
\end{array}$ & 3,570 & 2,098 & 1,980 & 1,623 & 1,454 & 1,420 & 1,183 \\
\hline$\%$ of Variance & 19,835 & 11,658 & 11,001 & 9,018 & 8,081 & 7,890 & 6,570 \\
\hline Cumulative $\%$ & 19,835 & 31,493 & 42,494 & 51,512 & 59,592 & 67,482 & 74,053 \\
\hline
\end{tabular}

The first factor explains $19.84 \%$ of the total variance. Here the following indicators significantly correlate - FAT\% (0.935), muscle mass (0.911), TBW\% (-0.894), height (0.660), height to failure (-0.528) (Figure 1).

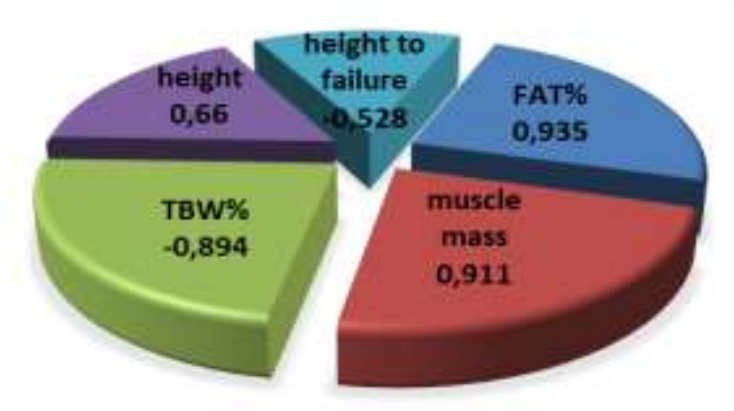

Figure 1. Invoice structure of the first factor of the incoming testing 
Tests TBW\% and higher to failure have negative signs, which means that have an inverse correlation. Due to the availability of sufficient indicators characterizing body mass composition, the first factor can be identified as "body mass composition".
The second factor explains $11.66 \%$ of the total variance. The following tests significantly correlate in this factor - Cooper's test (0.885), beep test (0.732), chest circumference difference (-0.553) (Figure 2).

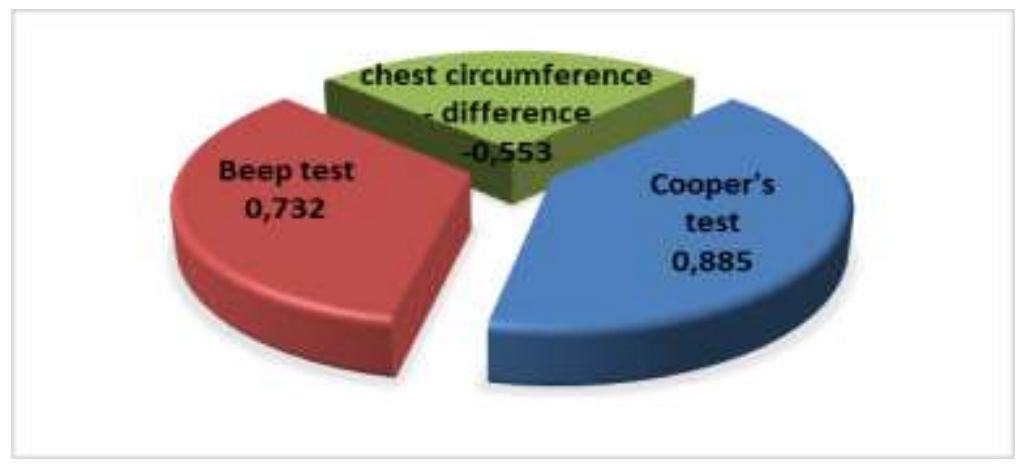

Figure 2. Factoral structure of the second factor of the incoming testing

Chest circuit test - the difference is negative. Both factors have a cumulative percentage of $31.49 \%$. This factor can be characterized as "general endurance".
The third factor explains $11 \%$ of the total variance. The following tests significantly correlate in this factor - plank (0.883), shuttle 10x10m (-0.989) (Figure 3).

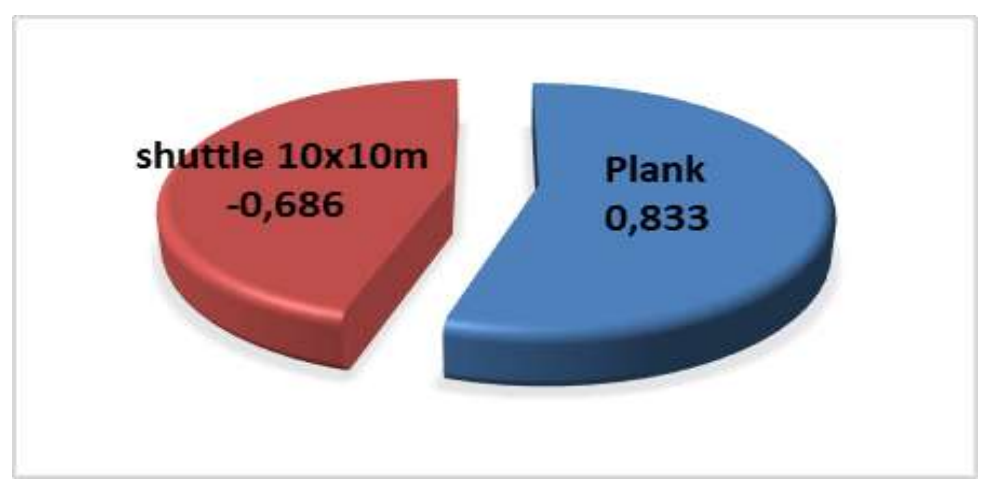

Figure 3. Factoral structure of the third factor of the incoming testing

The $10 \mathrm{x} 10 \mathrm{~m}$ shuttle test has a negative sign. The cumulative percentage of the three factors is $42.49 \%$. This factor can be defined as characterizing "special endurance".
The fourth factor explains $9.02 \%$ of the total variance. The following tests significantly correlate in this factor - step test - pulse onset $3 \mathrm{~min}$ from recovery (0.816), abdominal presses to failure (0.643), weight retention $2 \mathrm{~kg}$ (0.592) (Figure 4).

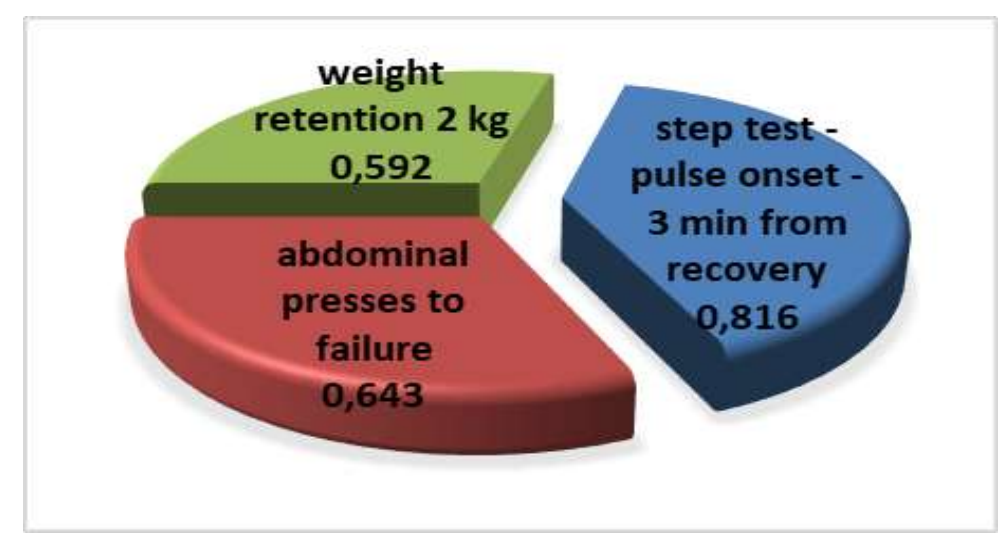

Figure 4. Invoice structure of the fourth factor of the incoming testing 
The cumulative percentage of the first four factors is $51.51 \%$. This factor can be defined as characterizing "strength endurance".

The fifth factor explains $8.08 \%$ of the total variance. In this factor the following tests significantly correlate - jump in length from place (0.859) and state force (0.528) (Figure 5).

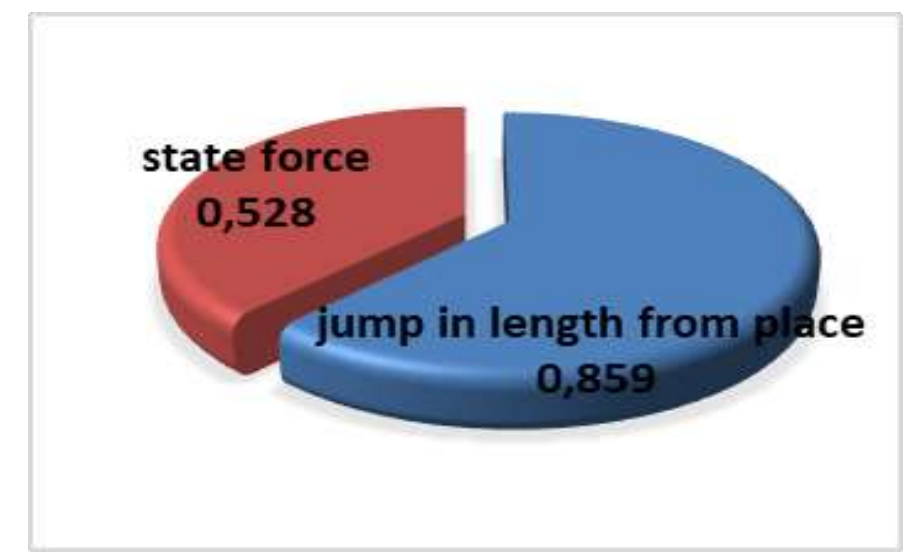

Figure 5. Invoice structure of the fifth factor of the incoming testing

The cumulative percentage of the first five factors is $59.59 \%$. This factor can be defined as characterizing the "explosive force of the lower extremities".
The sixth factor explains $7.89 \%$ of the total variance. The following tests significantly correlate in this factor - throwing a medical ball $(3 \mathrm{~kg})$ forward $(0.697)$ and FVC (0.630) (Figure 6).
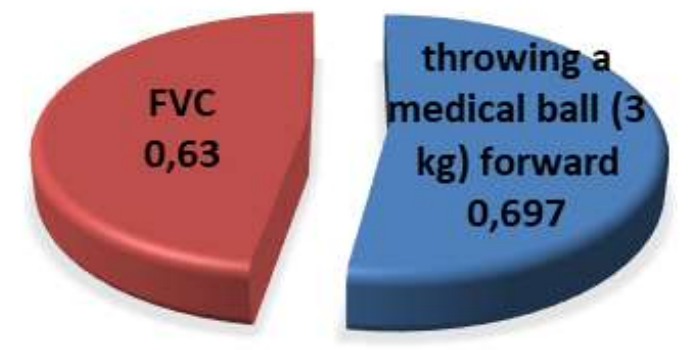

Figure 6. Factorial structure of six factors of incoming testing
The cumulative percentage of the first six factors is $67.48 \%$. This factor can be defined as characterizing the "explosive force of the upper extremities".

The seventh factor explains $6.57 \%$ of the total variance. There is only one test in this factor push-ups to knee failure (0.630).

All seven factors have a cumulative percentage of $74.05 \%$. This factor can be defined as "characterizing the strength endurance of the upper extremities".

The analysis of the results of the tests shows that there are four factors. The first weighs
4,188 , the second 3,301 , the third 2,088 , the fourth 1,922 . In total, all four factors explain $63.88 \%$ of the total variance. The data are shown in Table 2.

The first factor explains $23.27 \%$ of the total variance. Here the following indicators significantly correlate - plank (0.851), state force $(0.798)$, abdominal presses to failure (0.714), beep test $(0.660)$, shuttle $10 \times 10 \mathrm{~m} \mathrm{(-}$ 0.629), Kuper's test (0.611), Step test - pulse onset - 3rd minute from the recovery $(-0.557)$, Height to failure (0.485) (Figure 7). 
Table 2. Analysis of the main factors at the end of the experiment

\begin{tabular}{|c|c|c|c|c|}
\hline \multirow[b]{2}{*}{ Test } & \multicolumn{4}{|c|}{ Factors (components) } \\
\hline & 1 & 2 & 3 & 4 \\
\hline Plank & ,851 &,- 055 &,- 250 & ,024 \\
\hline State force & ,798 &, 144 &, 129 & ,133 \\
\hline Abdominal presses until failure & ,714 &,- 064 &,- 062 & ,313 \\
\hline Beep test &, 660 &,- 112 & ,257 & ,469 \\
\hline Running $10 \times 10 \mathrm{~m}$ & -.629 & -.044 & -.407 & .057 \\
\hline Kuper's test &, 611 &,- 024 &, 393 & .503 \\
\hline Step test - pulse onset - 3rd minute from the recovery &,- 557 &, 214 &,- 187 &,- 357 \\
\hline Height to failure &, 485 &,- 462 & ,281 &,- 158 \\
\hline FAT\% & 025 & ,891 &,- 204 &, 153 \\
\hline Muscle mass &,- 050 & 870 & ,229 &, 050 \\
\hline TBW\% &,- 010 &,- 814 & ,280 &,- 057 \\
\hline Height &, 074 &, 715 & ,233 &,- 299 \\
\hline Jump length from one place & ,452 &,- 456 & 185 &, 130 \\
\hline Chest circuit - difference & 074 &,- 142 & ,738 &,- 047 \\
\hline FVC &,- 087 &,- 053 & ,647 &, 425 \\
\hline Throwing a medical ball (3kg) forward & ,389 &, 101 &, 525 & ,082 \\
\hline Push-ups with knee supports until failure & ,193 & 014 & 016 & ,807 \\
\hline Dumbbell retention $2 \mathrm{~kg}$ & ,393 & ,181 & ,067 & ,449 \\
\hline Total & 4,188 & 3,301 & 2,088 & 1,922 \\
\hline$\%$ of Variance & 23,269 & 18,339 & 11,599 & 10,676 \\
\hline Cumulative \% & 23,269 & 41,607 & 53,206 & 63,882 \\
\hline
\end{tabular}

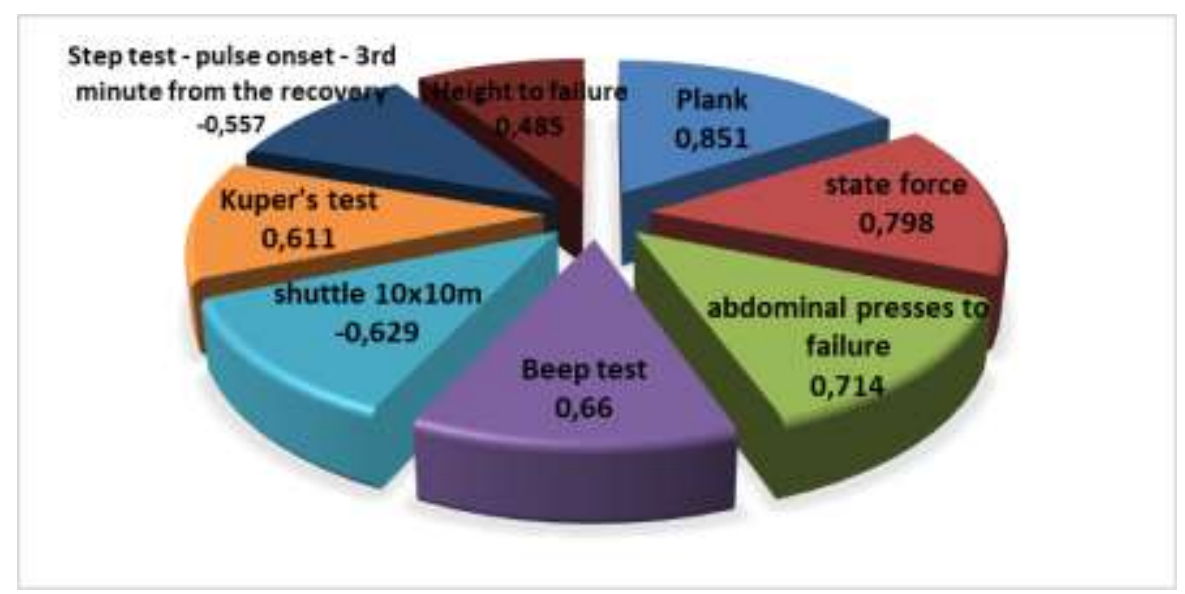

Figure 7. Factoral structure of the first factor of the outgoing testing

Step tests - pulse onset - the 3rd minute of recovery and the shuttle $10 \times 10 \mathrm{~m}$ are negative, i.e. have an inverse correlation. Due to the presence of sufficient indicators characterizing the first factor can be identified as "endurance".
The second factor explains $18.34 \%$ of the total variance. Here the following indicators significantly correlate - height to failure ($0.462)$, FAT\% (0.891), muscle mass (0.870), TBW\% (-0.814), height (0.715), jump in length from place (-0.456) (Figure 8).

Figure 8. Factoral structure of the second factor of the outgoing testing

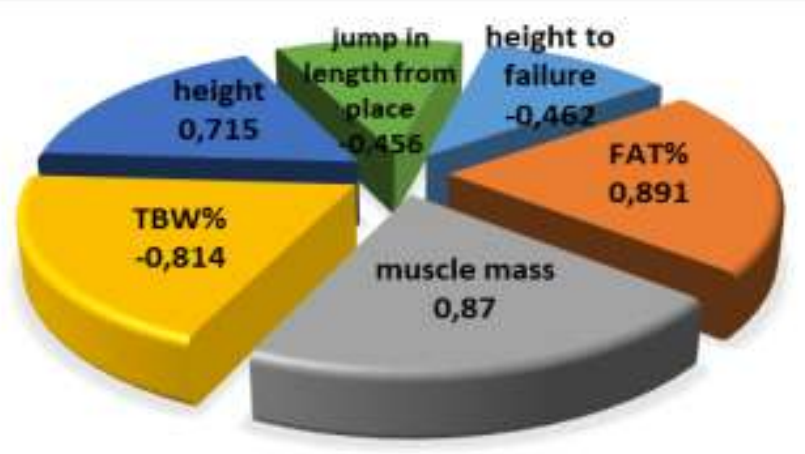


Tests jump length from one place to height to failure and TBW\% are negative. This factor can be defined as characterizing the "composition of body mass". This factor in the first study has the greatest intrinsic weight, and after conducting the experiment it is no longer of the greatest intrinsic importance. The failure test has enough weight to be in the first and second factor. This shows that the test correlates simultaneously with the tests of the two factors, but the correlation in the second factor is negative. The cumulative percentage of the first and second factors is $41.61 \%$.

The third factor explains $18.34 \%$ of the total variance. Here the following indicators significantly correlate - chest circumference difference (0.738), FVC (0.647), throwing a medical ball (3kg) forward (0.525) (Figure 9).

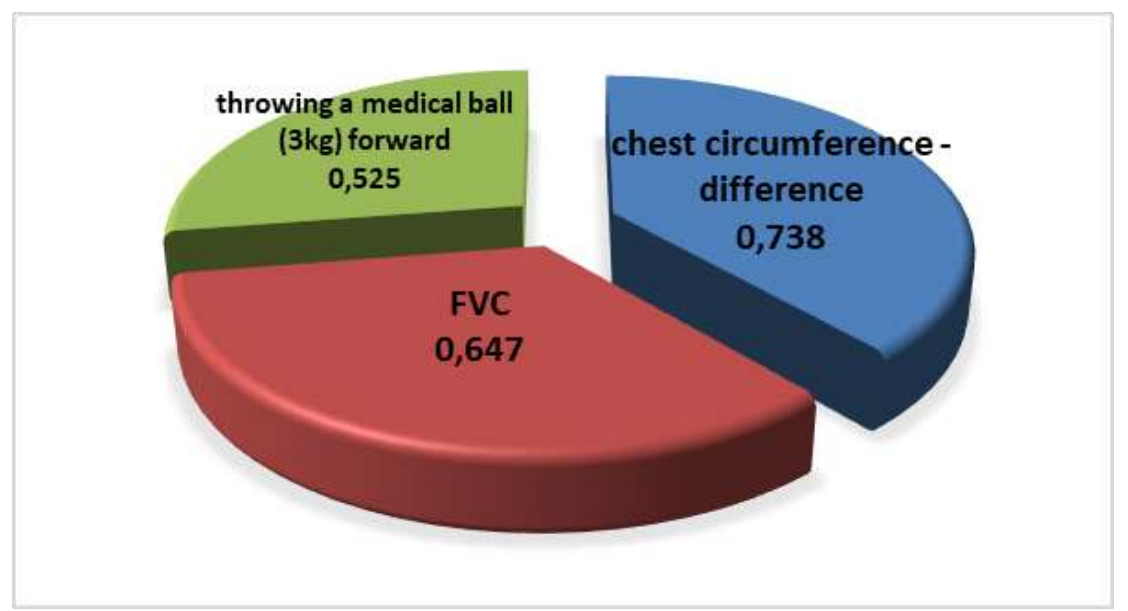

Figure 9. Factoral structure of the third factor of the outgoing testing

This factor can be defined as a characteristic "vital capacity". The cumulative percentage of the first three factors is $53.21 \%$.
The fourth factor explains $10.68 \%$ of the total variance. Here, the following indicators are significantly correlated - push-ups to knee failure (0.807), dumbbell retention $2 \mathrm{~kg}$ (0.449) (Figure 10).

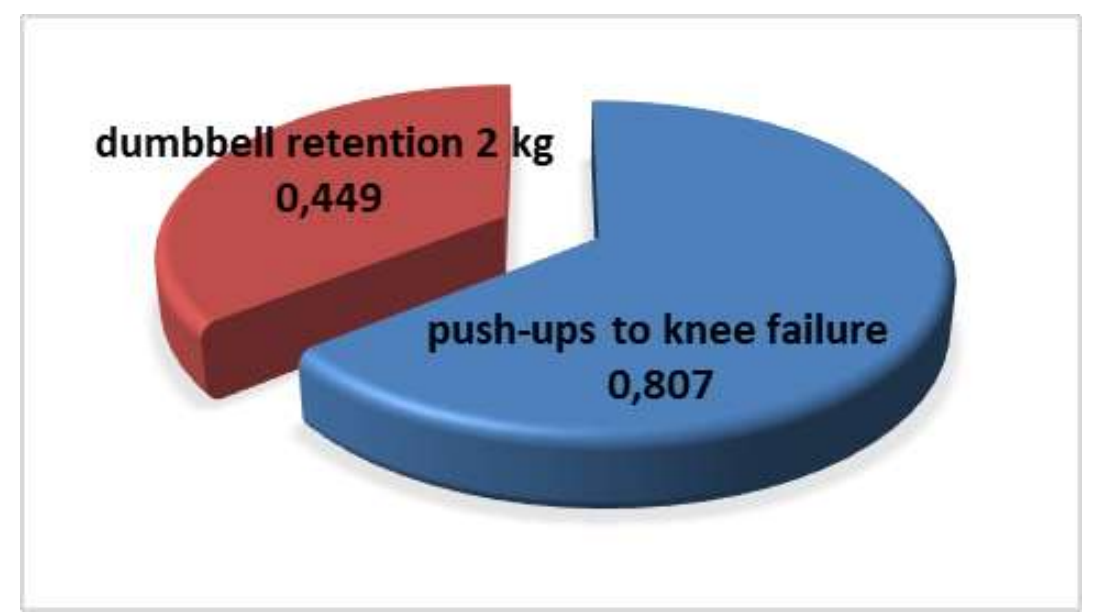

Figure 10. Factoral structure of the fourth factor of the outgoing testing

This factor can be defined as characterizing "strength endurance of the upper extremities". The cumulative percentage of the four factors is $69.88 \%$.

After the factor analysis the following conclusions can be summarized:

- In the applied fitness model, a decrease in the number of the main factors in the factor structure of the morphofunctional indicators and the observed motor qualities was observed in the experimental group.

- The increase in the influence of the first main factor in the second study explains the higher percentage of the cumulative variance. This in turn leads to 
structural changes in the content of the main factors.

- The influence of factors changes, which after the experiment increases the influence of endurance at the expense of body composition.

- The force factors retain approximately the same weight in the second study.

\section{REFERENCES}

1. Gigova, V., Damyanova, R., Statistical methods in sports - a guide for students with a bachelor's degree from NSA, Sofia, 2012

2. Hristova. V., Factor structure of physical condition in students aged 11 - 15 years, Sport and Science, 2005

3. Petkov, P., Specialized fitness training for students, Dissertation, 2019 